\title{
Кормовые добавки
}

\section{РОЛЬ КАРОТИНОИДОВ ПРИ БИОФОРТИФИКАЦИИ ПИЩЕВЫХ ЯИЦ КУР (Gallus gallus L.) (-3 ПОЛИНЕНАСЫЩЕННЫМИ ЖИРНЫМИ КИСЛОТАМИ, ВИТАМИНОМ Е И СЕЛЕНОМ*}

\author{
А.Ш. КАВТАРАШВИЛИ', Е.Н. НОВОТОРОВ¹, В.М. КОДЕНЦОВА², \\ Д.В. РИСНИК ${ }^{3}$
}

Естественное обогащение пищевых продуктов растительного и животного происхождения необходимыми для человека нутриентами (биофртификация) рассматривается в современной диетологии как альтернатива применению химически синтезируемых пищевых добавок. При получении биофортифицированных яиц кур корма в основном обогащают одним или двумя микронутриентами. Однако для большей части взрослого и детского населения планеты характерен одновременный недостаток сразу нескольких микронутриентов (витаминов, каротиноидов, минеральных веществ) и полиненасыщенных жирных кислот (ПНЖК). Кроме того, комплексное обогащение продуктов питания сбалансированным набором нутриентов позволяет не только компенсировать существующий дефицит, но и контролировать вторичные дефициты по тем веществам, потребность которых в организме может возрастать в результате изменения диеты. В настоящей работе нами выполнена биофортификация куриных яиц одновременно по четырем дефицитным микронутриентам, которые к тому же имеют неодинаковую химическую природу и обладают разными физиологическими свойствами. В рационе кур-несушек (порода Леггорн, кросс СП 789, 4 группы по $n=30$, содержание в клеточных батареях, длительность эксперимента 60 сут, 2019 год) во всех группах

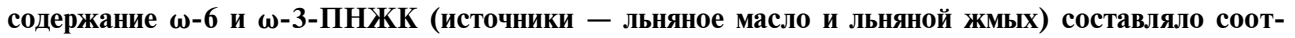
ветственно 2,18 и 1,97 \%, а их соотношение 1,11:1; витамина E (D-альфа-токоферол, концентрат) - 150 г, селена - 0,5 г/т (органический и неорганический 1:1, в форме Sel-Plex® и селенита натрия). В комбикорм опытных II, III и IV групп дополнительно вводили каротиноиды - соответственно 10, 14 и 18 г/т (в виде экстракта цветков бархатцев Tagetes erecta), а в контрольной I группе их фоновое содержание составляло 7,5 г/т. Введение в корм каротиноидов (на фоне постоянного состава трех остальных микронутриентов, испытанных нами ранее) существенно не отражалось на яичной продуктивности птицы (45,1-46,9 шт.), конверсии корма в продукцию $(1,58$ 1,63 кг на 10 яиц и 2,43-2,50 кг на 1 кг яичной массы), морфологических качествах яиц (масса яйца - 65,0-65,2 г, желтка - 18,1-18,3 г, белка $-39,3-39,7$ г, скорлупы - 7,0-7,1 г). Яйца, обогащенные одновременно четырьмя микронутриентами, не только представляют собой ценный пищевой продукт - источник лютеина, селена, ПНЖК и витамина Е, но и могут использоваться в качестве компонента при создании функциональных пищевых продуктов. Количество каротиноидов в яйце зависело от их уровня в корме птицы. За счет увеличения концентрации каротиноидов в желтке повышалась интенсивность его окраски в 1,66-1,84 раза, что улучшило товарный вид и потребительские качества яиц. В лучшей группе содержание каротиноидов в 100 г съедобной части яйца составило 0,7 мг, селена - 62 мкг, витамина $E-10$ мг, $\omega-3$ ПНЖК - 417 мг (при соотношении $\omega-6: \omega-3-3,1: 1)$, что соответственно в 3,$96 ; 1,62 ; 4,37$ и 2,42 раза выше, чем в необогащенных яйцах. Употребление одного яйца в сутки обеспечит дополнительное поступление в организм

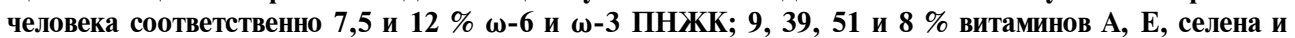
легкоусвояемых каротиноидов (преимущественно лютеина) от рекомендуемого количества.

Ключевые слова: биофортификация, каротиноды, куры, яйца, витамин Е, селен, линенасыщенные жирные кислоты.

Дефицит микронутриентов в питании снижает адаптационный потенциал человека, что создает риск развития многих болезней и негативно сказывается на работоспособности. Для большей части взрослого и детского населения характерен одновременный недостаток сразу нескольких микронутриентов (витаминов, каротиноидов, минеральных веществ) и дефицит потребления с пищей полиненасыщенных жирных кислот (ПНЖК), поэтому целесообразно одновременно обогащать пищевые продукты комплексом микронутриентов (1). Кроме того, комплексное обогащение позволяет из-

* Работа финансово поддержана РНФ, грант № 16-16-04047. 
бежать некоторых нежелательных последствий, которые могут возникнуть при биофортификации одним нутриентом. Например, известно, что дополнительный прием ПНЖК усиливает перекисное окисление липидов как в самом обогащаемом пищевом продукте, так и у человека, потребляющего такие продукты, в результате потребность организма в витамине Е повышается (2). Одновременное обогащение продукта ПНЖК и $\alpha$-токоферолом или каротиноидами, обладающими антиоксидантными свойствами (томатная паста), позволяет решить эту проблему $(3,4)$. Для обогащения яиц селеном используют как органические, так и неорганические формы этого микроэлемента $(5,6)$. В качестве источника ПНЖК применяют льняное семя (7), морские микроводоросли (8), рыбий жир (9).

Рекомендации по ограничению потребления куриных яиц из-за высокого содержания в них холестерина в настоящее время уже не носят столь строго характера. В частности, установлено, что низкое (менее 2 яиц в неделю), умеренное и даже высокое потребление яиц (4-7 шт. в неделю) не связано с повышенным риском сердечно-сосудистых заболеваний у пациентов с диабетом или без диабета, а также развитием метаболического синдрома (10-13), хотя некоторые авторы занимают более осторожную позицию (14). Употребление в течение 3 нед здоровыми молодыми людьми на завтрак по два яйца не оказало неблагоприятного влияния на биомаркеры, связанные с риском сердечно-сосудистых заболеваний (соотношение липопротеидов низкой и высокой плотности, концентрация глюкозы и триглицеридов в плазме крови). При этом субъективно отмечалось повышение чувства сытости в течение дня по сравнению с группой лиц, получавших на завтрак так называемые «быстрые» углеводы (овсяная каша) (15). Следовательно, куриное яйцо, ценность которого может быть повышена посредством обогащения корма кур-несушек микронутриентами (биофортификация), становится еще более привлекательным объектом для этих целей. Важное преимущество биофортификации заключается в том, что в организме кур происходит биотрансформация обогащающих добавок (витаминов, минеральных веществ) в их естественные формы.

Основными источниками лютеина в питании человека служат окрашенные овощи и фрукты, а также желток куриного яйца, из которого лютеин усваивается значительно лучше, чем из препаратов очищенного лютеина или лютеина из растительных источников (12). В человеческом организме лютеин сконцентрирован в макуле глаза и мозге (16). Лютеин - основной пищевой каротиноид, предотвращающий дегенерацию макулы при старении, улучшающий когнитивные функции, состояние сердечно-сосудистой системы, уменьшающий риск развития рака $(17,18)$ и обладающий противовоспалительным действием (19). Для обогащения продукции птицеводства каротиноидами в кормлении птицы часто используют либо натуральные порошки из высушенных томатов (20) и/или красного перца (21), травяные добавки, например экстракт цветков календулы (4), микроводоросль спирулину (22), либо каротинсодержащие препараты, полученные из растительного сырья $(12,23,24)$.

Анализ научных публикаций показывает, что при биофортификации в основном используется обогащение кормов кур одним $(8,9,20,24)$ или двумя микронутриентами $(4,5)$. В ранее проведенных исследованиях нами показана эффективность комплексного обогащения пищевых яиц тремя нутриентами - $\omega-3$ ПНЖК, витамином Е и селеном (10). В настоящем сообщении впервые представлены данные об одновременном обогащении 
куриных яиц четырьмя дефицитными микронутриентами, к тому же имеющими разную химическую природу и обладающими разными физиологическими свойствами. В доступной литературе подобных примеров мы не обнаружили.

Цель работы - изучить возможность одновременной биофортификации пищевых яиц каротиноидами, $\omega-3$ полиненасыщенными жирными кислотами, витамином Е и селеном посредством обогащения ими комбикормов кур-несушек и оценить влияние таких добавок на продуктивные качества птицы как интегральный показатель ее физиологического статуса и производственной эффективности предлагаемой биотехнологии.

Методика. Исследование проводили на курах промышленного стада кросса СП 789 (виварий Селекционно-генетического центра «Загорское экспериментальное племенное хозяйство» ВНИТИП, Московская обл., г. Сергиев Посад, 2019 год). Для этого методом аналогов сформировали 4 группы (по $n=30$ ) 300-суточных кур. Птицу до 360-суточного возраста (с 19 июня по 18 августа 2019 года) содержали в клеточных батареях («FACCO», Италия) по 3 гол. в клетке, площадь пола клетки - 450 см²/особь.

Рацион всех групп имел следующий состав (на 1 т комбикорма): пшеница - 57,61 \%, соя экструдированная полуобезжиренная - 9,82 \%, шрот подсолнечный $-12,12 \%$, жмых льняной $-5,0 \%$, масло льняное $3,0 \%$, жирные кислоты - 1,5\%. Содержание $\omega-6-$ и $\omega-3$ ПНЖК составило соответственно 2,18 и 1,97 \%, их соотношение - 1,11:1; содержание витамина $\mathrm{E}-150$ г, селена - 0,5 г на 1 т комбикорма. В рацион контрольной I группы каротиноиды дополнительно не вводили, их естественное содержание составило 7,5 г/т корма. В качестве источника селена в рационах использовали селеносодержащие дрожжи Sel-Plex® («Alltech», США), в которых селен находится в виде селенометионина (50\%) и селеноцистина (25\%), а также селенит натрия в соотношении 1:1. В качестве источника витамина Е использовали продукт переработки отходов масложировой промышленности Жирные кислоты (ООО «АВК-ХИМ», Россия) с содержанием жира $90 \%$, $\alpha$-токоферола - не менее 11,3 мг/г, натуральных каротиноидов - 280 мкг/г. В рационы всех групп вводили ферментные препараты Фидбест W (содержит ксиланазу и $\beta$-глюканазу) и Фидбест Р (содержит 3фитазу) (по 100 г/т корма; ООО «Сиббиофарм», Россия). В рацион опытных II, III и IV групп в качестве источника каротиноидов добавляли экстракт цветков бархатцев (Tagetes erecta) (Биофон желтый, «Биокол Агро», Россия) с содержанием каротиноидов 20 г/кг (85\% лютеина и $15 \%$ зеаксантина) в количестве соответственно 500, 700 и 900 г (10, 14 и 18 г каротиноидов) на 1 т комбикорма.

Регистрировали следующие показатели: сохранность поголовья посредством ежедневного учета павшей птицы; живую массу птицы - индивидуальным взвешиванием всего поголовья в 300- и 360-суточном возрасте; яйценоскость на начальную и среднюю несушку - на основании расчета по данным ежесуточного учета снесенных яиц по группам; массу яиц - индивидуальным взвешиванием всех яиц от каждой группы, снесенных курами за 3 сут подряд через 30 и 60 сут с начала опыта; выход яичной массы на начальную и среднюю несушку - методом расчета по результатам учета числа снесенных яиц и средней массы одного яйца по группам; потребление корма - ежесуточным учетом заданного корма и его остатков в конце каждой недели; затраты корма на 10 яиц и на 1 кг яичной массы - по данным учета потребления корма, яйценоскости и выхода яичной массы; 
массу белка, желтка, скорлупы - раздельным индивидуальным взвешиванием составных частей яйца через 30 и 60 сут после начала опыта; соотношение белок:желток - по данным учета массы белка и желтка яиц; интенсивность окраски желтка яиц - индивидуальной оценкой по цветовой шкале фирмы BASF через 30 и 60 сут после начала исследования. В эти же сроки определяли содержание в желтке каротиноидов, витаминов А, Е и В2,

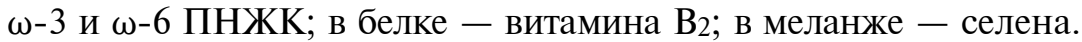

При определении суммы каротиноидов и жирорастворимых витаминов в желтке яиц применяли единую пробоподготовку, которая заключалась в омылении образцов 50 \% раствором гидроксида калия с последующей экстракцией диэтиловым эфиром («Биологический контроль при инкубировании яиц сельскохозяйственной птицы: методические наставления». Сергиев Посад, 2014). Массовую долю витаминов А и Е определяли методом нормально-фазной высокоэффективной жидкостной хроматографии (хроматографическая система Knauer advanced scientific instruments, «Knauer Engineering $\mathrm{GmbH}$ Industrieanlagen \& Со.», Германия) в соответствии с Р 4.1.1672-03 «Руководство по методам контроля качества и безопасности биологически активных добавок к пище» (М., 2003), сумму каротиноидов колориметрически (фотометр КФК-3-01, «ЗОМЗ», Россия) с использованием бихромат калия для построения калибровочного графика с измерением OD450 (синий светофильтр). Длины волн 292 и 450 нм могут использоваться для количественного определения витамина А и каротина, так как в этой области спектры поглощения практически не перекрываются (25). Компоненты разделяли на колонке Luna $5 \mu \mathrm{m}$ Silica(2) 100 A New Column $150 \times 4,6$ mm («Phenomenex, США), элюировали смесью гексан:изопропиловый спирт (98:2), детекцию витамина А и Е выполняли соответственно при 292 и 324 нм, в качестве стандартов использовали препараты Retinol Sigma кат. № R 7632 («Sigma-Aldrich», США) и (+/-)- $\alpha$-Tocopherol Fluka кат. № 95240 («Fluka», Германия).

Водорастворимый витамин В2 (рибофлавин) в желтке и белке яиц определяли флуорографически с использованием анализатора жидкости Флюорат-02-3М (НПФНП «Люмэкс», РФ). Пробоподготовка заключалась в спиртовой экстракции (из белка $96 \%$ этанолом, из желтка 55 \% этанолом) с последующей фильтрацией через бумажный среднепористый фильтр («желтая полоса»). Измеряли интенсивность флуоресценции полученных растворов в ультрафиолетовых лучах, концентрацию рибофлавина рассчитывали относительно рабочего стандартного раствора витамина В2.

Содержание селена в меланже определяли методом атомно-абсорбционной спектрометрии с электротермической атомизацией (спектрометр Duo 240 FS/240Z, «Varian», США). Для разложения образцов использовали микроволновую систему пробоподготовки Milestone START D («Milestone Systems», Италия); модификатор - 1 \% раствор нитрата никеля $\mathrm{Ni}\left(\mathrm{NO}_{3}\right)_{2}$. Калибровочный график строили по разведениям раствора стандартного

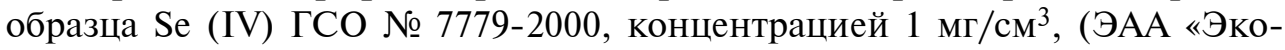
аналитика», Россия).

Массовую долю сырого жира определяли по Рэндаллу с использованием экстрактора VELP Ser148 («VELP», Италия), жирнокислотный состав - капиллярной газожидкостной хроматографией на газовом хроматографе Кристалл-2000М (ЗАО СБК «Хроматек», Россия). Экстрагированные липиды переэтерифицировали с помощью кислотного катализатора (хлористый водород) в присутствии избытка метилового спирта. Жирные 
кислоты в форме метиловых эфиров разделяли на капиллярной колонке Stabilwax®-DA («Restek», CША) (длина 60 м, внутренний диаметр 0,32 мм, толщина фазы 0,5 мкм) и регистрировали с помощью пламенно-ионизационного детектора Кристалл 2000М (ЗАО СБК «Хроматек», Россия). Стандартом для определения жирных кислот служил набор CRM47885 («SigmaAldrich», США). Массовую долю индивидуальной жирной кислоты от суммы жирных кислот определяли методом внутренней нормализации.

Данные обрабатывали методами вариационной статистики в программе Microsoft Excel. В таблицах и на рисунке представлены средние $(M)$ и их стандартные ошибки ( $\pm \mathrm{SEM})$. Статистическую значимость различий между группами оценивали по $t$-критерию Стьюдента при р $<0,05$.

Результаты. Выполненные исследования (табл. 1) показали, что за 60-суточный период содержания сохранность птицы во всех группах составила $100 \%$. Значительных различий между группами по живой массе кур в 360-суточном возрасте и средней массе яиц за период опыта мы не отмечали. По данным чешских ученых (26), добавление в рацион несушек экстракта лютеина (90 \%) в дозе 250 мг/кг достоверно повышал массу яиц, толщину и прочность скорлупы.

1. Продуктивность кур-несушек кросса СП 789 при обогащении рационов нутриентами с целью биофортификации ( $M \pm \mathrm{SEM}$, виварий Селекционно-генетического центра «Загорское экспериментальное племенное хозяйство» ВНИТИП, Московская обл., г. Сергиев Посад, 2019 год)

\begin{tabular}{|c|c|c|c|c|}
\hline \multirow[b]{2}{*}{ Показатель } & \multicolumn{4}{|c|}{ Группа } \\
\hline & $\begin{array}{l}\text { I (контроль, } \\
n=30)\end{array}$ & II $(n=30)$ & III $(n=30)$ & IV $(n=30)$ \\
\hline Сохранность поголовья, \% & 100 & 100 & 100 & 100 \\
\hline \multicolumn{5}{|l|}{ Живая масса птицы в разном возрасте, г: } \\
\hline 300 сут & $1579 \pm 24$ & $1577 \pm 23$ & $1579 \pm 13$ & $1574 \pm 24$ \\
\hline 360 сут & $1650 \pm 33$ & $1722 \pm 29$ & $1701 \pm 28$ & $1674 \pm 23$ \\
\hline \multicolumn{5}{|l|}{ Яйценоскость на начальную и среднюю } \\
\hline несушку, шт. & $45,1 \pm 4,2$ & $45,8 \pm 3,8$ & $46,3 \pm 5,1$ & $46,9 \pm 4,9$ \\
\hline Интенсивность яйценоскости, \% & $75,2 \pm 6,8$ & $76,3 \pm 5,3$ & $77,2 \pm 6,6$ & $78,2 \pm 7,1$ \\
\hline Средняя масса яиц, г & $65,0 \pm 0,5$ & $65,1 \pm 0,6$ & $65,2 \pm 0,4$ & $65,1 \pm 0,4$ \\
\hline Выход яичной массы на несушку, кг & $2,93 \pm 0,32$ & $2,98 \pm 0,27$ & $3,02 \pm 0,45$ & $3,05 \pm 0,38$ \\
\hline \multicolumn{5}{|l|}{ Расход корма: } \\
\hline на 1 гол/сут, г & $122,2 \pm 11,3$ & $122,2 \pm 12,2$ & $122,8 \pm 10,9$ & $123,5 \pm 11,5$ \\
\hline на 10 яиц, кг & $1,63 \pm 0,12$ & $1,60 \pm 0,11$ & $1,59 \pm 0,09$ & $1,58 \pm 0,11$ \\
\hline на 1 кг яичной массы, кг & $2,50 \pm 0,31$ & $2,46 \pm 0,28$ & $2,44 \pm 0,26$ & $2,43 \pm 0,34$ \\
\hline
\end{tabular}

Самую высокую яйценоскость и выход яичной массы на несушку зарегистрировали в IV группе - соответственно на 1,3-4,0 и 1,2-4,3 \% больше, чем в остальных группах. Минимальными эти показатели были в контроле (І группа). Сообщалось $(27,28)$, что включение в рацион кур-несушек экстракта цветков календулы или кукурузного глютена как источника каротиноидов позволило повысить яйценоскость кур на 7-14 \%. По данным других авторов (29), ни вид источника лютеина (мука из цветков бархатцев и гидролизованный экстракт этой муки, в котором эфиры лютеина были подвергнуты омылению), ни его доза в рационе (10, 20, 30 и 40 г/т) не оказали достоверного влияния на продуктивность несушек и основные показатели качества яиц.

Расход корма на 1 гол/сут был наименьшим в контроле и во II группе - на 0,65-1,05 \% ниже, чем в III и IV группах, при максимальном показателе в IV группе. Кроме того, более высокая яйценоскость и выход яичной массы обусловили снижение затрат кормов на 10 яиц и 1 кг яичной 
массы в этой группе соответственно на 0,63-3,07 и 0,41-2,80 \% по сравнению с другими группами. Наибольшими были затраты кормов в контроле.

Данные, представленные в таблице 2, показывают, что в среднем за период опыта (60 сут) по абсолютной и относительной массе желтка, белка и скорлупы яиц, содержанию в скорлупе кальция, в желтке - витаминов A, Е и $\mathrm{B}_{2}$ и в белке - витамина $\mathrm{B}_{2}$, а также соотношению массы белка и желтка между группами не было статистически значимых различий. По содержанию селена, $\omega-3$ ПНЖК и соотношению $\omega-6$ и $\omega-3$ группы различались незначительно. Отмечена не достигающая статистической значимости тенденция к увеличению содержания витамина Е в желтке яиц при увеличении дозы каротиноидов в рационе, что может свидетельствовать об их определенном синергизме.

2. Морфологические показатели яиц и содержание в них микронутриентов у курнесушек кросса СП 789 при обогащении рационов с целью биофортификации ( $M \pm \mathrm{SEM}$, виварий Селекционно-генетического центра «Загорское экспериментальное племенное хозяйство» ВНИТИП, Московская обл., г. Сергиев Посад, 2019 год)

\begin{tabular}{|c|c|c|c|c|}
\hline \multirow[b]{2}{*}{ Показатель } & \multicolumn{4}{|c|}{ Группа } \\
\hline & $\begin{array}{l}\text { I (контроль, } \\
n=30)\end{array}$ & II $(n=30)$ & III $(n=30)$ & $\mathrm{IV}(n=30)$ \\
\hline \multicolumn{5}{|l|}{ Macca: } \\
\hline желтка, г & $18,1 \pm 0,2$ & $18,2 \pm 0,2$ & $18,2 \pm 0,2$ & $18,3 \pm 0,1$ \\
\hline желтка, \% & 28,0 & 28,2 & 28,0 & 28,3 \\
\hline белка, г & $39,5 \pm 0,3$ & $39,3 \pm 0,4$ & $39,7 \pm 0,3$ & $39,3 \pm 0,2$ \\
\hline белка, \% & 61,0 & 60,9 & 61,2 & 60,8 \\
\hline скорлупы, г & $7,1 \pm 0,1$ & $7,0 \pm 0,1$ & $7,0 \pm 0,1$ & $7,0 \pm 0,2$ \\
\hline Скорлупы, \% & 11,0 & 10,9 & 10,8 & 10,9 \\
\hline Интенсивность окраски желтка, балл & $3,8 \pm 0,1$ & $6,3 \pm 0,2^{*}$ & $6,7 \pm 0,2^{*}$ & $7,0 \pm 0,3^{*}$ \\
\hline Соотношение массы белка и желтка & 2,2 & 2,2 & 2,2 & 2,1 \\
\hline \multicolumn{5}{|l|}{ Содержание: } \\
\hline в скорлупе кальция, \% & $36,6 \pm 3,3$ & $36,6 \pm 2,4$ & $36,1 \pm 3,8$ & $36,4 \pm 2,9$ \\
\hline \multicolumn{5}{|l|}{ в желтке, мкг/г } \\
\hline каротиноидов & $5,6 \pm 1,1$ & $13,0 \pm 2,6^{*}$ & $14,4 \pm 2,9 *$ & $21,9 \pm 4,4^{*}$ \\
\hline витамина А & $4,2 \pm 0,3$ & $4,1 \pm 0,4$ & $4,5 \pm 0,2$ & $4,6 \pm 0,5$ \\
\hline витамина Е & $283 \pm 21$ & $290 \pm 17$ & $306 \pm 23$ & $315 \pm 29$ \\
\hline витамина В2 & $5,6 \pm 0,4$ & $6,5 \pm 0,7$ & $5,8 \pm 0,2$ & $5,8 \pm 0,4$ \\
\hline в белке витамина В2, мкг/г & $3,9 \pm 0,4$ & $4,3 \pm 0,3$ & $4,3 \pm 0,6$ & $4,3 \pm 0,4$ \\
\hline \multicolumn{5}{|c|}{ Содержание в 100 г съедобной части яйца: } \\
\hline каротиноидов, мкг & $177 \pm 35$ & $424 \pm 85$ & $454 \pm 91$ & $701 \pm 140$ \\
\hline селена, мкг & $62 \pm 0,7$ & $61 \pm 0,7$ & $62 \pm 0,9$ & $62 \pm 1,1$ \\
\hline витамина Е, мг & $8,9 \pm 0,9$ & $9,5 \pm 1,2$ & $9,6 \pm 0,8$ & $10,1 \pm 1,4$ \\
\hline 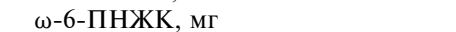 & $1093 \pm 52$ & $1075 \pm 75$ & $1140 \pm 67$ & $1298 \pm 111$ \\
\hline$\omega$-3-ПНЖК, мг & $347 \pm 19$ & $393 \pm 31$ & $412 \pm 43$ & $417 \pm 28$ \\
\hline Соотношение $\omega-6$ к $\omega-3$ ПНЖК & $3,1: 1$ & $2,7: 1$ & $2,8: 1$ & $3,1: 1$ \\
\hline \multicolumn{5}{|c|}{$\begin{array}{l}\text { П р и м е ч а н и е. ПНЖК - полиненасыщенные жирные кислоты. Описание состава рационов, обогащен- } \\
\text { ных каротиноидами, } \omega-3 \text { полиненасыщенными жирными кислотами, витамином Е и селеном, по группам } \\
\text { см. в разделе «Методика». } \\
\text { * Различия с показателями в контрольной группе статистически значимы при } \mathrm{p}<0,05 \text {. }\end{array}$} \\
\hline
\end{tabular}

Наши данные не согласуются с результатами других авторов (26), которые отмечали достоверное повышение содержания в желтке витамина А и снижение концентрации витамина Е при включении в рацион несушек экстракта порошка лютеина (250 г/т), что может быть обусловлено значительно меньшим количеством экстракта, вводимого нами в рацион (10-18 г/т). Также отметим, что в более поздней работе этих же авторов (30) при включении в рацион кур-несушек экстракта цветков бархатцев содержание витамина Е оставалось на уровне контроля.

Следует отметить, что в лучшей группе (IV группа) содержание в 100 г съедобной части яйца каротиноидов составило 0,7 мг, селена - 62 мкг, витамина Е - 10 мг, $\omega-3$ ПНЖК - 417 мг (при соотношении $\omega-6: \omega-3-$ 
$3,1: 1)$, что соответственно в 3,96 (p<0,05), 1,62 (p<0,001), 4,37 (p<0,01) и 2,42 (p < 0,001) раза выше, чем в необогащенных яйцах (10).

Анализ интенсивности окраски желтка и содержания каротиноидов в желтке яиц кур при разном содержании каротиноидов в рационе показал (рис.), что в первом случае зависимость имеет вид кривой насыщения с постепенным подъемом с максимумом, в 3,9 раза превышающим показатель в контрольной группе $(\mathrm{p}<0,05)$. Аналогично с увеличением дозы каротиноидов в рационе достоверно повышалось их содержание в желтке куриного яйца. Доза каротиноидов около 20 г/т корма обеспечивала достижение их максимальной концентрации в яичном желтке. Обогащение корма птицы каротиноидами сопровождалось повышением их количества в желтке до значений, характерных для яиц птицы, потребляющей рационы с увеличенным содержанием этих микронутриентов $(29,31,32)$.

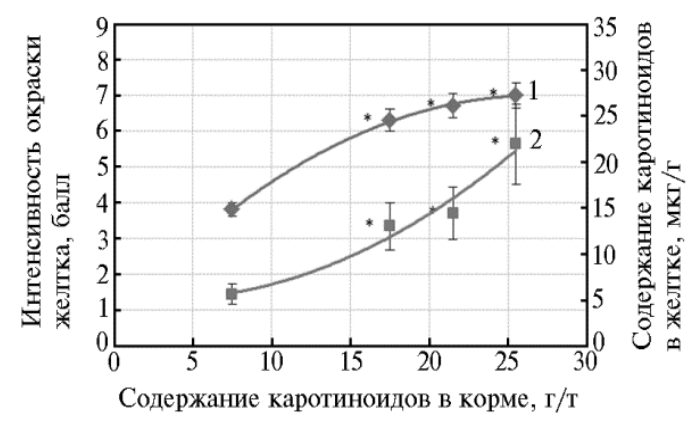

3. Микронутриентная ценность пищевых яиц кур-несушек кросса СП 789 при обогащении ращионов с целью биофортификации ( $M \pm \mathrm{SEM}$, виварий Селекционно-генетического центра «Загорское экспериментальное племенное хозяйство» ВНИТИП, Московская обл., г. Сергиев Посад, 2019 год)

\begin{tabular}{l|c|c|c}
\hline Микронутриент & $\begin{array}{l}\text { Рекомендуемое потребление } \\
\text { (адекватное потребление) }\end{array}$ & $\begin{array}{l}\text { Содержание в одном обога- } \\
\text { щенном яйце (IV группа) }\end{array}$ & $\begin{array}{l}\text { Стень удовлетворе- } \\
\text { нияребности, \% }\end{array}$ \\
\hline Каротиноиды & $(5$ мг) & 0,4 мг & 8 \\
Селен & $55-70$ мкг & 35,7 мкг & 51 \\
Витамин Е & 15 мг & 5,8 мг & 39 \\
Витамин А & 900 мкг & 84 мкг & 9 \\
$\omega-6$ ПНЖК & $(10$ г) & 0,748 г & 7,5 \\
$\omega-3$ ПНЖК & $(2$ г) & 0,240 г & 12
\end{tabular}

П р и м е ч н и е. ПНЖК - полиненасыщенные жирные кислоты. Описание состава рационов, обогащенных каротиноидами, $\omega-3$ полиненасыщенными жирными кислотами, витамином Е и селеном, по группам см. в разделе «Методика».

Мы оценили полученные данные по биофортификации куриных яиц в связи с пищевой ценностью для человека (табл. 3) в процентах относительно рекомендуемого (33) или адекватного уровня потребления (34). Употребление в сутки одного яйца, полученного в результате комплексной биофиртификации, обеспечит поступление 7,5 и 12,0 \% $\omega-6$ и $\omega-3$ ПНЖК (при их соотношении $3,1: 1)$ от рекомендуемого или адекватного уровня потребления, $39 \%$ - витамина Е и $51 \%$ - селена. Таким образом, полученные яйца соответствуют критериям для обогащенной микронутриентами пищевой продукции. Что касается каротиноидов, то их содержание в яйце повысилось в 4 раза, достигнув $8 \%$ от адекватного суточного потребления. В сравнительных исследованиях, проведенных E.R. Kelly с соавт. (35), было установлено, что 0,9 мг содержащегося в яйце лютеина по эффективности повышения его уровня в плазме крови добровольцев соответствуют 5 мг 
того же каротиноида, поступающего из биологически активной добавки. Учитывая, что лютеин из желтка яиц усваивается значительно лучше, чем из растительных источников (12), можно считать, что пищевая ценность полученного нами продукта существенно повысилась.

Вместе с тем следует обратить внимание на тот факт, что потребление двух яиц, с одной стороны, позволит превысить $15 \%$ от рекомендуемого потребления для каротиноидов и витамина А, то есть нижнюю границу, позволяющую отнести полученную продукцию к категории обогащенной, однако, с другой стороны, при этом потребление селена (хотя и в менее опасной органической форме) достигнет $100 \%$ от нормы физиологической потребности. Принимая во внимание, что селен содержится и в других продуктах питания, представляется целесообразным несколько уменьшить его содержание в рационе кур-несушек (верхний допустимый предел потребления для взрослого человека - 150 мкг/сут) (33).

Использование желтков с максимальным содержанием селена, ПНЖК, витамина Е и лютеина, позволит повысить микронутриентную ценность этого компонента не только при непосредственном употреблении в пищу. Обогащенные микронутриентами яйца могут служить хорошим сырьем для получения меланжа - компонента функциональных пищевых продуктов. В экспериментах на животных показано, что каротиноиды хорошо усваиваются из обогащенных ими яиц (36). Высокая сохранность (около 85 \% от содержания в сыром яйце) каротиноидов в яичнице из яиц, обогащенных за счет скармливания курам богатого каротиноидами зерна кукурузы (37), показывает, что термически обработанные яйца могут служить источником этих микронутриентов в питании населения. Не менее устойчивы при варке яиц ПНЖК (38). Потребление обогащенных ПНЖК яиц (6 шт. в неделю) в течение 8 нед сопровождалось повышением содержания докозагексаеной кислоты в мембранах эритроцитов у здоровых добровольцев (39). Добавление сваренных целиком яиц оказалось эффективным способом увеличения абсорбции $\alpha$ - и $\gamma$-токоферола из салата из свежих овощей у здоровых молодых людей (40). Свойство фосфолипидов желтка куриного яйца выступать в роли «транспортного средства» для каротиноидов использовали при создании компонента на основе желтков, тыквы и моркови для обогащения каротиноидами творожных продуктов и молочного напитка (41).

Итак, результаты исследования показали, что одновременное добавление в корм кур-несушек каротиноидов, $\omega-3$ полиненасыщенных жирных кислот (ПНЖК), соединений селена и витамина Е приводит к существенному повышению содержания этих микронутриентов в яйцах. При этом за счет увеличения содержания в желтке каротиноидов его окраска становится более интенсивной, что улучшает товарный вид и потребительские качества яиц. Добавление в корм каротиноидов (на фоне постоянного состава трех остальных микронутриентов, испытанных нами ранее) существенно не отражалось на яичной продуктивности птицы (45,1-46,9 шт.), конверсии корма (1,58-1,63 кг на 10 яиц и 2,43-2.50 кг на 1 кг яичной массы) и морфологических качествах яиц (масса яйца - 65,0-65,2 г, желтка - 18,1-18,3 г, белка - 39,3-39,7 г, скорлупы - 7,0-7,1 г), но сопровождалось увеличением в 2,40-3,96 раза содержания каротиноидов. Следует отметить, что в лучшей группе содержание каротиноидов в 100 г съедобной части яйца составило 0,7 мг, селена - 62 мкг, витамина Е - 10 мг, $\omega-3$ ПНЖК -417 мг $(\omega-6: \omega-3-3,1: 1)$, что соответственно в 3,96 (p<0,05), 1,62 (p<0,001), 4,37 
$(\mathrm{p}<0,01)$ и $2,42(\mathrm{p}<0,001)$ раза выше, чем в необогащенных яйцах. Употребление одного яйца в сутки обеспечит дополнительное поступление в организм человека 7,5 и 12 \% $\omega-3$ и $\omega-6$ ПНЖК, 9, 39, 51 и 8 \% - соответственно витамина А, витамина Е, селена и легкоусвояемых каротиноидов (преимущественно лютеина) от рекомендуемой дозы. Обогащенные одновременно четырьмя микронутриентами яйца могут использоваться не только как ценный натуральный пищевой продукт - источник лютеина, селена, ПНЖК и витамина Е, но также как компонент при создании функциональных пищевых продуктов, в том числе способствующий усвоению других компонентов рациона.

\author{
1 ФНЦ Всероссийский научно-исследовательский \\ и технологический институт птицеводства РАН, \\ 141311 Россия, Московская обл., г. Сергиев Посад, ул. Птицеградская, 10, \\ e-mail: alexk@vnitip.ru $\bowtie$, en-5506040@mail.ru; \\ 2ФГБУН Федеральный исследовательский иентр питания, \\ биотехнологии и безопасности пищи, \\ 119240 Россия, г. Москва, Устьинский пр., 2/4, \\ e-mail: kodentsova@ion.ru; \\ ЗФГБОУ ВО Московский государственный \\ университет им. М.В. Ломоносова, \\ Биологический факультет, \\ 119234 Россия, г. Москва, Ленинские горы, МГУ, 1, стр. 12, \\ Биологический факультет МГУ, \\ e-mail: biant3@mail.ru
}

Поступила в редакцию 13 декабря 2019 года

Sel'skokhozyaistvennaya biologiya [Agricultural Biology], 2020, V. 55, № 4, pp. 738-749

\title{
THE ROLE OF CAROTENOIDS IN THE BIOFORTIFICATION OF TABLE CHICKEN (Gallus gallus L.) EGGS WITH $\omega$-3 POLYUNSATURATED FATTY ACIDS, VITAMIN E, AND SELENIUM
}

\author{
A.Sh. Kavtarashvili' ${ }^{1}$, E.N. Novotorov' ${ }^{1}$, V.M. Kodentsova ${ }^{2}$, D.V. Risnik ${ }^{3}$
}

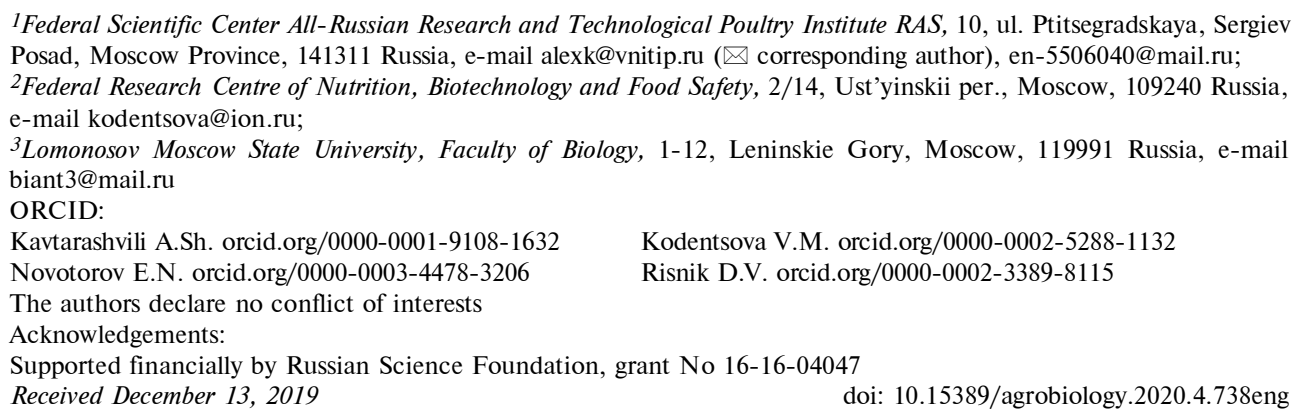

\section{Abstract}

Natural fortification of plant and animal derived foodstuffs with essential nutrients (biofortification) is regarded by modern nutritional science as an effective alternative for the synthetic food additives. Biofortified eggs are usually enriched with one or two target micronutrients via layer diets. However, the nutrition of the large part of the World's population (both adult and infant) is characterized by the simultaneous deficiencies of different micronutrients: vitamins, carotenoids, minerals, and polyunsaturated fatty acids (PUFAs). The combined enrichment of foodstuffs with balanced set of the essential nutrients can compensate for these deficiencies and control the secondary deficiencies of the nutrients which can become deficient due to the changes in the diets of the patients. In the study presented the combined biofortification of table chicken eggs with four deficient micronutrients with different chemical and physiological properties was examined. The trial was performed in 2019 on four treatments of cage-housed Leghorn laying hens (Gallus gallus L., cross SP 789, 30 birds per treatment) during 60 days of the productive period. The concentrations of $\omega-6$ and $\omega-3$ PUFAs (from flaxseed oil and cake) in the diet for control treatment 1 were 2.18 and $1.97 \%$, respectively, $\omega-6 / \omega-3$ 
ratio 1.11:1; the diet was also supplemented with vitamin $\mathrm{E}(150 \mathrm{ppm}$, as concentrated $\mathrm{D}$ - $\alpha$-tocopherol) and selenium (0.5 ppm as 1:1 mixture of organic (Sel-Plex $\left.{ }^{\circledR}\right)$ and inorganic (sodium selenite) forms); the background concentration of carotenoids in this diet was $7.5 \mathrm{ppm}$. Treatments 2,3 , and 4 were fed the same diet additionally supplemented with $10 ; 14$ and $18 \mathrm{ppm}$ of carotenoids (as extract of the marigold, Tagetes erecta), respectively. The supplementation with carotenoids of diets containing the constant combination of other three target micronutrients (that we have studied in our previous trials) did not significantly affect the egg production (45.1-46.9 eggs per hen during 60 days of the trial), feed conversion ratios (1.58-1.63 kg of feed per 10 eggs and 2.43-2.50 kg of feed per $1 \mathrm{~kg}$ of eggs laid), and egg weight and morphology (average egg weight 65.0-65.2 g, yolk weight 18.1-18.3 g, albumen weight 39.3-39.7 g, eggshell weight 7.0-7.1 g) in layers. The eggs simultaneously fortified with the four micronutrients can be the valuable source of luthein, selenium, PUFAs, and vitamin E in human diet; these eggs could be also used as a component of multi-ingredient functional foodstuffs. The concentration of carotenoids in eggs increased with the increase in their concentration in layer diets. The increase in the concentration of the carotenoids in yolk enhanced the intensity of yolk coloration 1.66-1.84-fold, improving the market appearance and consumer attractibility of the eggs. The concentration of the four target micronutrients (per $100 \mathrm{~g}$ of edible part of the eggs) in the eggs from the treatment fed the highest dietary level of carotenoids were $0.7 \mathrm{mg}$ for carotenoids, $62 \mu \mathrm{g}$ for selenium, $10 \mathrm{mg}$ for vitamin E, $417 \mathrm{mg}$ for $\omega-3$ PUFAs (with $\omega-6 / \omega-3$ ratio 3.1:1), 3.96; 1.62; 4.37 and 2.42 times higher, respectively, in compare to "standard" (non-fortified) eggs. The daily consumption of one fortified egg will provide a consumer with 7.5 and $12 \%$ of recommended daily consumption of $\omega-6$ and $\omega-3$ PUFAs, respectively, as well as $9 ; 39 ; 51$ and $8 \%$ of recommended daily consumption of vitamin A, vitamin E, selenium, and easily digestible carotenoids (primarily, lutein), respectively.

Keywords: biofortification, lutein, chickens, eggs, vitamin E, selenium, $\omega-3$ PUFA.

\section{REFEREN C ES}

1. Kodentsova V.M., Risnik D.V., Stefanova I.L. Ptitsa i ptitseprodukty, 2019, 1: 27-29 (doi: 10.30975/2073-4999-2019-21-1-27-29) (in Russ.).

2. Raederstorff D., Wyss A., Calder P. C., Weber P., Eggersdorfer M. Vitamin E function and requirements in relation to PUFA. British Journal of Nutrition, 2015, 114(8): 1113-1122 (doi: 10.1017/S000711451500272X).

3. Kavtarashvili A.Sh., Stefanova I.L., Svitkin V.S., Novotorov E.N. Functional egg production. I. The role of $\omega-3$ polyunsaturated fatty acids (review). Agricultural Biology [Sel'skokhozyaistvennaya biologiya], 2017, 52(2): 349-366 (doi: 10.15389/agrobiology.2017.2.349eng).

4. Panaite T.D., Nour V., Vlaicu P.A., Ropota M., Corbu A.R., Saracila M. Flaxseed and dried tomato waste used together in laying hens diet. Archives of Animal Nutrition, 2019, 73(3): 222-238 (doi: 10.1080/1745039X.2019.1586500).

5. Leeson S., Namkung H., Caston L., Durosoy S., Schlegel P. Comparison of selenium levels and sources and dietary fat quality in diets for broiler breeders and layer hens. Poultry Science, 2008, 87(12): 2605-2612 (doi: 10.3382/ps.2008-00174).

6. Kavtarashvili A.Sh., Stefanova I.L., Svitkin V.S., Novotorov E.N. Functional egg production. II. The roles of selenium, zinc, and iodine (review). Agricultural Biology [Sel'skokhozyaistvennaya biologiya], 2017, 52(4): 700-715 (doi: 10.15389/agrobiology.2017.4.700eng).

7. Weill P., Schmitt B., Chesneau G., Daniel N., Safraou F., Legrand P. Effects of introducing linseed in livestock diet on blood fatty acid composition of consumers of animal products. Annals of Nutrition and Metabolism, 2002, 46(5): 182-191 (doi: 10.1159/000065405).

8. Lemahieu C., Bruneel C., Termote-Verhalle R., Muylaert K., Buyse J., Foubert I. Impact of feed supplementation with different omega-3 rich microalgae species on enrichment of eggs of laying hens. Food Chemistry, 2013, 141(4): 4051-4059 (doi: 10.1016/j.foodchem.2013.06.078).

9. Cachaldora P., García-Rebollar P., Alvarez C., Blas J.D., Méndez J. Effect of type and level of fish oil supplementation on yolk fat composition and n-3 fatty acids retention efficiency in laying hens. British Poultry Science, 2006, 47(1): 43-49 (doi: 10.1080/00071660500475541).

10. Mazo V.K., Kavtarashvili A.Sh., Stefanova I.L., Kodentsova V.M., Bagryantseva O.V., Svitkin V.S., Novotorov E.N., Risnik D.V., Mokshantseva I.V., Sidorova Yu.S., Zorin S.N., Klimenkova A.Yu. Funktsional'nye yaitseprodukty [Functional egg products]. Moscow, 2018 (in Russ.).

11. Díez-Espino J., Basterra-Gortari F.J., Salas-Salvady J., Buil-Cosiales P., Corella D., Schröder H., Estruch R., Ros E., Gómez-Gracia E., Arys F., Fiol M., Lapetra J., Serra-Majem L., Pinty X., Babio N., Quiles L., Fito M., Marti A., Toledo E. Egg consumption and cardiovascular disease according to diabetic status: The PREDIMED study. Clinical Nutrition, 2017, 36(4): 1015 1021 (doi: 10.1016/j.clnu.2016.06.009).

12. Chung H.Y., Rasmussen H.M., Johnson E.J. Lutein bioavailability is higher from lutein- 
enriched eggs than from supplements and spinach in men. The Journal of Nutrition, 2004, 134(8): 1887-1893.

13. Park S.J., Jung J.H., Choi S.W., Lee H.J. Association between egg consumption and metabolic disease. Korean Journal for Food Science of Animal Resources, 2018, 38(2): 209-223 (doi: 10.5851/kosfa.2018.38.2.209).

14. Mah E., Chen C.O., Liska D.J. The effect of egg consumption on cardiometabolic health outcomes: an umbrella review. Public Health Nutrition, 2020, 23(5): 935-955 (doi: 10.1017/S1368980019002441).

15. Missimer A., DiMarco D.M., Andersen C.J., Murillo A.G., Vergara-Jimenez M., Luz Fernandez M. Consuming two eggs per day, as compared to an oatmeal breakfast, decreases plasma ghrelin while maintaining the LDL/HDL ratio. Nutrients, 2017, 9(2): 89 (doi: 10.3390/nu9020089).

16. Lieblein-Boff J.C., Johnson E.J., Kennedy A.D., Lai C.S., Kuchan M.J. Exploratory metabolomic analyses reveal compounds correlated with lutein concentration in frontal cortex, hippocampus, and occipital cortex of human infant brain. PLoS ONE, 2015, 10(8): e0136904 (doi: 10.1371/journal.pone.0136904)

17. Buscemi S., Corleo D., Di F.P., Petroni M.L., Satriano A., Marchesini G. The effect of lutein on eye and extra-eye health. Nutrients, 2018, 10(9): 1321 (doi: 10.3390/nu10091321).

18. Ames B.N. Prolonging healthy aging: longevity vitamins and proteins. Proceedings of the National Academy of Sciences, 2018, 115(43): 10836-0844 (doi: 10.1073/pnas.1809045115).

19. Chung R.W.S., Leanderson P., Lundberg A.K., Jonasson L. Lutein exerts anti-inflammatory effects in patients with coronary artery disease. Atherosclerosis, 2017, 262: 87-93 (doi: 10.1016/j.atherosclerosis.2017.05.008).

20. Akdemir F., Orhan C., Sahin N., Sahin K., Hayirli A. Tomato powder in laying hen diets: effects on concentrations of yolk carotenoids and lipid peroxidation. British Poultry Science, 2012, 53(5): 675-680 (doi: 10.1080/00071668.2012.729142).

21. Omri B., Alloui N., Durazzo A., Lucarini M., Aiello A., Romano R., Santini A., Abdouli H. Egg yolk antioxidants profiles: effect of diet supplementation with linseeds and tomato-red pepper mixture before and after storage. Foods, 2019, 8(8): 320 (doi: 10.3390/foods8080320).

22. Zahroojian N., Moravej H., Shivazad M. Comparison of marine algae (Spirulina platensis) and synthetic pigment in enhancing egg yolk colour of laying hens. British Poultry Science, 2011, 52(5): 584-588 (doi: 10.1080/00071668.2011.610779).

23. Afanas'ev G.D., Popova L.A., Komarchev A.S., Trepak Zh.G. Ptitsa i ptitseprodukty, 2014, 5: $62-$ 64 (in Russ.).

24. Kavtarashvili A.Sh., Stefanova I.L., Svitkin V.S. Functional egg production. III. The role of the carotenoids (review). Agricultural Biology [Sel'skokhozyaistvennaya biologiya], 2019, 54(4): 681-693 (doi: 10.15389/agrobiology.2019.4.681eng).

25. Mokshina N.Ya., Khokhlov V.Yu., Shlyakhina Yu.V., Selemenov V.F. Vestnik VGU. Seriya: KHimiya, Biologiya, Farmatsiya, 2003, 2: 53-55 (in Russ.).

26. Englmaierová M., Skřivan M., Bubancová I. A comparison of lutein, spray-dried Chlorella, and synthetic carotenoids effects on yolk colour, oxidative stability, and reproductive performance of laying hens. Czech J. Anim. Sci., 2013, 58(9): 412-419 (doi: 10.17221/6941-CJAS).

27. Koshchaev A.G. Khranenie i pererabotka sel'khozsyrya, 2007, 2: 34-38 (in Russ.).

28. Skřivan M., Marounek M., Englmaierova M., Skřivanova E. Effect of increasing doses of marigold (Tagetes erecta) flower extract on eggs carotenoids content, colour and oxidative stability. Journal of Animal and Feed Sciences, 2016, 25: 58-64 (doi: 10.22358/jafs/65588/2016).

29. Lokaewmanee K., Yamauchi K., Komori Ts., Saito K. Enhancement of yolk color in raw and boiled egg yolk with lutein from marigold flower meal and marigold flower extract. The Journal of Poultry Science, 2011, 48(1): 25-32 (doi: 10.2141/jpsa.010059).

30. Skřivan M., Englmaierová M., Skřivanová E., Bubancová I. Increase in lutein and zeaxanthin content in the eggs of hens fed marigold flower extract. Czech J. Anim. Sci., 2015, 60(3): 89-96 (doi: 10.17221/8073-CJAS).

31. Kodentsova V.M., Vrzhesinskaya O.A., Beketova N.A., Kodentsova O.V. Voprosy pitaniya, 2005, 5: 19-24 (in Russ.).

32. Kavtarashvili A.Sh., Mazo V.K., Kodentsova V.M., Risnik D.V., Stefanova I.L. Biofortification of hen eggs: vitamins and carotenoids (review). Agricultural Biology [Sel'skokhozyaistvennaya biologiya], 2017, 52(6): 1094-1104 (doi: 10.15389/agrobiology.2017.6.1094eng).

33. MR 2.3.1.2432-08. Normy fiziologicheskikh potrebnostei v energii i pishchevykh veshchestvakh dlya razlichnykh grupp naseleniya Rossiiskoi Federatsii. Metodicheskie rekomendatsii [MR 2.3.1.2432-08. Norms of energy and nutrient physiological requirements for various groups of the population of the Russian Federation. Guidelines]. Moscow, 2009 (in Russ.).

34. Edinye sanitarno-epidemiologicheskie i gigienicheskie trebovaniya $k$ tovaram, podlezhashchim sanitarno-epidemiologicheskomu nadzoru (kontrolyu) Tamozhennogo soyuza EvrAzES (Prilozhenie 5) [Uniform sanitary, epidemiological and hygienic requirements for goods subject to sanitary and 
epidemiological supervision (control) of the EurAsEC Customs Union (Appendix 5)]. Moscow, 2010 (in Russ.).

35. Kelly E.R., Plat J., Haenen G.R., Kijlstra A., Berendschot T.T. The effect of modified eggs and an egg-yolk based beverage on serum lutein and zeaxanthin concentrations and macular pigment optical density: results from a randomized trial. PLoS ONE, 2014, 9(3): e92659 (doi: 10.1371/journal.pone.0092659).

36. Heying E.K., Ziemer K.L., Tanumihardjo J.P., Palacios-Rojas N., Tanumihardjo S.A. $\beta$-Cryptoxanthin-biofortified hen eggs enhance vitamin A status when fed to male Mongolian Gerbils. The Journal of Nutrition, 2018, 148(8): 1236-1243 (doi: 10.1093/jn/nxy117).

37. Sowa M., Yu J., Palacios-Rojas N., Goltz S.R., Howe J.A., Davis C.R., Rocheford T., Tanumihardjo S.A. Retention of carotenoids in biofortified maize flour and $\beta$-cryptoxanthinenhanced eggs after household cooking. ACS Omega, 2017, 2(10): 7320-7328 (doi: 10.1021/acsomega.7b01202).

38. Douny C., Khoury R.E., Delmelle J., Brose F., Degand G., Moula N., Farnir F., Clinquart A., Maghuin-Rogister G., Scippo M.-L. Effect of storage and cooking on the fatty acid profile of omega-3 enriched eggs and pork meat marketed in Belgium. Food Science \& Nutrition, 2015, 3(2): 140-152 (doi: 10.1002/fsn3.197).

39. Burns-Whitmore B., Haddad E., Sabaté J., Rajaram S. Effects of supplementing n-3 fatty acid enriched eggs and walnuts on cardiovascular disease risk markers in healthy free-living lacto-ovovegetarians: a randomized, crossover, free-living intervention study. Nutrition Journal, 2014, 13(1): 29 (doi: 10.1186/1475-2891-13-29).

40. Kim J.E., Ferruzzi M.G., Campbell W.W. Egg consumption increases vitamin E absorption from co-consumed raw mixed vegetables in healthy young men. The Journal of Nutrition, 2016, 146(11): 2199-2205 (doi: 10.3945/jn.116.236307).

41. Bessonova L.N., Antipova L.V., Cherkasova A.V. V sbornike: Nauka, pitanie i zdorov'e [In: Science, nutrition and health]. Minsk, 2019: 480-487 (in Russ.). 